\title{
THE FUTURE IS BRIGHT WITH OPTICS
}

\section{MODERN SOCIETY IS INCREASINGLY RELIANT ON DEVICES THAT RUN ON LIGHT, BUT THERE'S A GLOBAL SHORTAGE OF OPTICS AND PHOTONICS TECHNICIANS. DR ALEXIS VOGT OF MONROE COMMUNITY COLLEGE HAS CREATED THE 'OPT-IN!' PROGRAMME, THE AIM OF WHICH IS TO DEVELOP $M U C H-N E E D E D$ TALENT IN THIS IMPORTANT FIELD}

\section{WHAT'S THE ISSUE?}

Thanks to optics and photonics, new technologies are advancing at what seems like breakneck speed. High speed internet, barcodes, laser tattoo removal, pacemakers, video surveillance systems, video streaming (and much, much more) all rely on photonics; and the technologies of the future will be even more reliant on these light-centric breakthroughs: solar power, driverless cars, laser surgery...

\section{The optics and photonics industries are} growing by more than 3\% per year. And 20\% of experienced technicians and engineers are approaching retirement, meaning there are more jobs available in the industry than ever before. Unfortunately, there aren't enough skilled STEM graduates to fill these vacancies. For example:

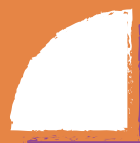

of Upstate New York optics technician job

\section{$75 \%$}

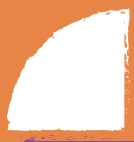

of small and mid-sized German companies report that their shortage of skilled
Whether it's telecommunications, medical imaging or cancer research, the vital technologies of today are reliant on the science of light: optics and photonics; and yet there's a serious shortage of experts with the appropriate skills to work in these areas. Consequently, there is a push to find passionate students of STEM, and to encourage them to take up careers in optics and photonics. But doing so is not just about filling a void. Optics technicians can make a real difference. They are at the forefront of innovation and design in many areas such as medicine, national security, manufacturing and renewable energy.

In recognition of the wonderful opportunities available in optics and photonics, Dr Alexis Vogt of Monroe Community College (MCC) created 'OPT-IN!' - a programme designed to strengthen the optics and photonics workforce to fill high-skilled, high-demand positions, and provide students with employment opportunities in regional industries.

\section{WHAT DOES OPT-IN!}

\section{DO DIFFERENTLY?}

The shortage of optics and photonics experts has lot to do with the lack of suitable education and training programmes. While MCC had been running a two-year degree programme in optics since 1971, Alexis wanted to boost the intake of students into the programme with an updated curriculum, a variety of course delivery models and state-of-the-art laboratory resources. She also wanted to provide professional development, strengthen industry partnerships and broaden community awareness of educational and employment opportunities in the fields of optics and photonics.

The OPT-IN! programme aims to connect more high school and college students with industry - and to produce the skilled workforce needed to keep up with demands. Another noteworthy difference is that OPTIN! offers internships and expands outreach efforts to underrepresented populations in the industry, including women and minority groups.

HOW DOES OPT-IN!

SUPPORT STUDENTS FROM

UNDERREPRESENTED GROUPS?

OPT-IN! has several recruitment, retention and outreach initiatives to build awareness of the programme, including the development of a portable Optics Road Show and other public presentations. Presentations have been developed for both general audiences and audiences from historically underrepresented populations such as women, African

Americans, Latinos, and those from low income backgrounds.

WHAT HAS OPT-IN!

ALREADY ACHIEVED?

As a testament to the effectiveness of OPTIN! and its recruitment strategies, 17 students graduated from MCC's optics programme in May 2018. That is, in fact, a $325 \%$ increase 


\section{ABOUT OPTICS \\ AND PHOTONICS}

Optics is the field of science and

engineering that deals with the origin,

movement and detection of light. As

for photonics, it's a term to describe the application of optics to perform functions that traditionally fall within the domain of electronics, such as telecommunications and information processing.

To illustrate the difference between the two, imagine you're buying vegetables at a grocery store. You can buy just broccoli, or you can buy an entire assortment of vegetables - broccoli, corn, spinach, peas, squash and so on. The field of photonics could be likened to the broccoli, while all the vegetables collectively represent optics. In other words, photonics is a branch of optics.

\section{WHY DO WE NEED}

PHOTONICS AND OPTICS EXPERTS?

Light is used in devices such as computers, smartphones and medical instruments. It can make these faster, smaller and more energy efficient. Wouldn't we all want our devices faster, smaller and more energy efficient? Light can even be used to manoeuvre DNA and other types of nanoparticles to research cures for cancer. So, we need to get the word out that optics and photonics is an exciting and productive career path.
WHAT DOES AN OPTICS AND PHOTONICS TECHNICIAN DO?

An optics and photonics technician works with scientists and engineers in research, development, design, manufacturing and quality control. Optics and photonics technicians hold the critical roles of manufacturing optics and performing testing and evaluation of optical components and systems. Optics companies cannot ship products out their doors without optics and photonics technicians.

\section{WHAT SKILLS AND PASSIONS DO}

YOU NEED TO BE AN OPTICS AND PHOTONICS TECHNICIAN?

Optics and photonics technicians work extensively with their hands to manufacture and measure optical components and systems. Research has shown that musicians, gamers, chefs, artists and mechanics make excellent optics and photonics technicians because of their demonstrated hand-eye coordination.

\section{WHAT OTHER CAREER}

OPPORTUNITIES ARE THERE

IN THIS FIELD?

An Associate Degree in Optics from MCC opens the doors to your career. Many go on to directly work in the optics industry for a company around the world. Some MCC graduates have, with their associate degree, advanced through their career to become CEOs of optics companies. Graduates may also find positions in:

\section{Academic institutions}

- Government laboratories

Technical sales

- Law firms

- Entertainment

Business management

- Politics and advisory boards

Other graduates spend two years at MCC and then transfer to a four-year university for two additional years to pursue a Bachelor of Science in Optics or Imaging Science.

WHAT'S SO GREAT ABOUT WORKING IN OPTICS AND PHOTONICS?

Working in optics and photonics means you are working with cutting-edge technology that enhances people's lives.

66 Optics and
photonics is one of
the most amazing
careers in the world
and not enough
people know it
exists as a discipline
of study! 99

\section{OPPORTUNITIES IN OPTICS AND PHOTONICS}

- Corning Incorporated launched a Technician Pipeline Program, which includes a salary of $\$ 25,000 /$ year for 8 hours of work per week, a two-year scholarship to earn a Degree in Optical Systems Technology at MCC, and conversion to a fulltime technician role at Corning Incorporated upon completion of the programme

\section{- Other companies such as Optimax, OptiPro, JML Optical, Schott and APOMA offer optics-related apprenticeships}

- Skilled optics and photonics technicians can make over $\$ 100,000$ with a twoyear Associate in Applied Science Degree from Monroe Community College 


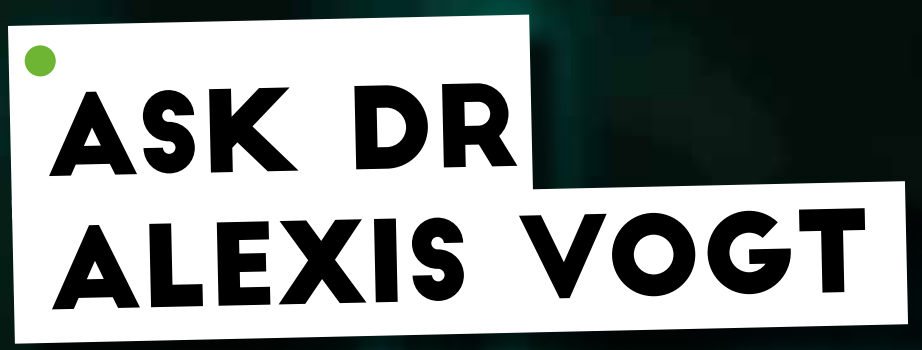

WHAT DID YOU WANT TO BE WHEN YOU WERE YOUNGER?

At a young age I said I wanted to be a kindergarten teacher. Apparently, I had the teaching part right, but the subject matter wrong. Instead of teaching students the fundamentals of reading, I'm teaching students how to read highly technical read-outs and data!

WHO OR WHAT INSPIRED YOU TO FOLLOW A CAREER IN OPTICS AND PHOTONICS?

The origin of my career in optics can be traced to my freshman year at the University of Rochester. Heeding the advice of friends who spoke highly of a professor who taught an introductory course in optics, I signed up for his class. I took the Intro to Optics course and the professor, Turan Erdogan, was fantastic. His ability to distil and convey complex optics principles in a compelling and engaging way was remarkable. He's a brilliant leader, accomplished businessman, family-focused and faith-filled man; he has inspired and motivated me since my optics career began.

WHICH SUBJECTS DID YOU STUDY AT UNIVERSITY?

My undergraduate degree is in optics from the Institute of Optics at the University of Rochester. I also completed my PhD in optics at the University of Rochester.

WHAT ADVICE WOULD YOU GIVE TO SOMEONE WHO IS STARTING OUT ON THEIR CAREER PATH?

My advice to someone starting out is to work hard, ask questions and always treat everyone with respect. The only limit to what you can do is your own ambition.
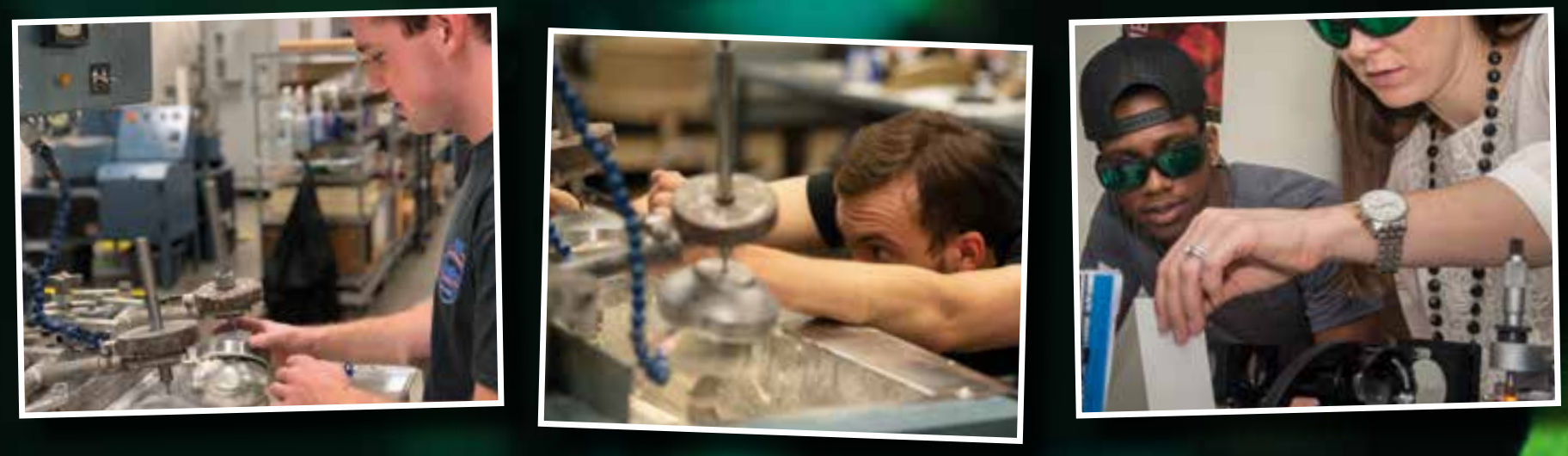